\title{
PENDAMPINGAN DALAM PENGEMBANGAN PENILAIAN AUTENTIK UNTUK MENINGKATKAN KINERJA GURU DI WILAYAH BINAAN TANGERANG
}

\author{
Riyan Arthur ${ }^{1)}$, Santoso Sri Handoyo ${ }^{2)}$, dan Daryati ${ }^{3)}$ \\ Prodi Pendidikan Teknik Bangunan, Fakultas Teknik, Universitas Negeri Jakarta \\ Email : arthur@unj.ac.id ${ }^{1)}$, santoso handoyo@unj.ac.id ${ }^{2)}$, daryati_sr@unj.ac.id ${ }^{3)}$
}

\begin{abstract}
The purpose of this assistance is to provide a knowledge and practice basis for conducting authentic assessments and technical guidance in preparing and carrying out authentic assessments. Mentoring is done to improve the ability to conduct assessments, especially authentic assessments for teachers, so that teachers can understand and apply authentic assessments in the process of evaluating teaching and learning activities in schools. This place of assistance is at SMK Negeri 4 South Tangerang, the time of assistance on August 4 to Sept 1, 2018 the method used in the activities of the event include lectures, brainstorming, question and answer, workshops, assignments and live demonstrations. The mentoring results show that $80 \%$ the teacher of SMK Negeri 4 Tangerang understands the concept of authentic assessment as indicated by the work of the teacher in the form of test and non-test instruments which are reported to refer to authentic evaluation models of authentic evaluation rubrics. The results of this assistance were immediately reported to the principal and witnessed by the school supervisor as a facilitator
\end{abstract}

Keywords : authentic, assesment, mentoring, teacher

\begin{abstract}
ABSTRAK
Tujuan dari pendampingan ini adalah untuk memberikan dasar pengetahuan dan praktik dalam melakukan penilaian autentik serta bimbingan teknik dalam menyusun dan melaksanakan penilaian autentik. Pendampingan dilakukan untuk meningkatkan kemampuan dalam melakukan penilaian khususnya penilaian autentik bagi guru, sehingga para guru dapat memahami dan menerapkan penilaian autentik dalam proses evaluasi kegiatan belajar mengajar di sekolah. Tempat pendampingan ini di SMK Negeri 4 Tangerang, waktu pendampingan tanggal 4 Agustus-1 September 2018 metode yang digunakan dalam kegiatan pendampingan antara lain dengan ceramah, brainstorming, tanya jawab, workshop, penugasan dan demonstrasi langsung. Hasil pendampingan menunjukkan bahwa guru SMK Negeri 4 Tangerang Selatan menggunakan konsep penilaian autentik hal itu ditunjukkan dengan hasil karya guru berupa penyusunan instrumen tes maupun non tes yang dilaporkan sebanyak $80 \%$ guru sudah mengacu pada model-model penilaian dan rubrik penilaian autentik. Hasil dari pendampingan ini langsung dilaporkan kepada kepala sekolah dan disaksikan oleh pengawas sekolah sebagai fasilitator
\end{abstract}

Kata Kunci : autentik, guru, pendampingan, penilaian

\section{PENDAHULUAN}

Kualitas pembelajaran merupakan suatu yang patut untuk ditingkatkan seiring dengan kebutuhan masyarakat dan tantangan global dewasa ini. Komitmen kelembagaan dan sistem pembelajaran yang efektif dengan memperhatikan konsistensi jalannya program pendidikan utamanya dalam tahap evaluasi merupakan satu hal yang penting untuk dicermati. pada proses pembelajaran setidaknya terkait dalam beberapa komponen, yaitu tujuan pembelajaran, kemampuan (perilaku) awal, proses pembelajaran, hasil 
belajar, evaluasi program pembelajaran dan umpan balik.

Seiring dengan kebutuhan akan pendidikan yang berkualitas, guru ditantang untuk meningkatkan kinerjanya . Kinerja guru atau prestasi kerja (performance) merupakan hasil yang dicapai oleh guru dalam melaksanakan tugas-tugas yang dibebankan kepadanya yang didasarkan atas kecakapan, pengalaman dan kesungguhan serta penggunaan waktu. Kinerja seorang guru akan baik jika telah melaksanakan unsur-unsur yang terdiri dari sikap yang positif, kecerdasan emosional yang stabil dan komitmen yang tinggi pada tugas mengajar, menguasai dan mengembangkan bahan pelajaran, kedisiplinan dalam mengajar, kreativitas dalam pelaksanaan pengajaran, kerja sama dengan semua warga sekolah, kepemimpinan dan kepribadian yang menjadi panutan siswa, jujur dan obyektif dalam membimbing siswa, serta tanggung jawab terhadap tugasnya. Oleh karena itu, penting untuk diadakan evaluasi kinerja bagi guru. Selain untuk meningkatkan kinerja guru itu sendiri, evaluasi juga diharapkan dapat menjadi bahan masukan untuk para pengambil keputusan agar kebijakan yang diambil sesuai dengan aturan yang berlaku dan tidak merugikan kepentingan pendidikan.

Authentic assessment activities are designed to mimic the complexity of 'real world' situations that students may encounter in professional life, and require the application of a combination of skills related to knowledge, skills and attitude (Raymond, Homer, Smith, \& Gray, 2013, p. 1) The educational assessment must be based on authentic and significant tasks and must be able to provide feedback for the individuals involved in the assessment process, in primes teachers and lipupils (Calenda \& Tammaro, 2015, p. 3891)

Penilaian autentik terjadi di dalam kelas dan pendekatan penilaiannya dapat bervariasi, karena tidak dibatasi sekedar paper and pencil tests (saja). Penilaian autentik dengan demikian sangat erat kaitannya dengan pembelajaran dan sangat mungkin dipakai untuk memantau proses belajar siswa. Keterkaitan ini memunculkan kondisi kelas seperti yang disebut (Brookhart, 2003) sebagai "Intergration of assessment and instruction". Jika pendapat tersebut sesuai, maka penilaian autentik pada dasarnya adalah penilaian kelas, yang mengambil bentuk tidak sekedar ujian tulis tetapi lebih bervariasi sehingga mencakup pengamatan langsung guru terhadap kinerja siswa, pemberian tugas-tugas pembelajaran dan sebagainya. Penilaian seperti ini dapat lebih berpusat kepada siswa, dan dapat melibatkan siswa secara langsung untuk menilai (penguasaan) kompetensi mereka sendiri atau teman satu kelasnya.

Authentic assessment pedagogy can be inferred to as a purposeful reflective process that involves the praxis of both thoughts and actions. (Chong, Lim, Liu, Lau, \& Wu, 2016) When designing an assessment it is important to ensure the objectives of the assessment are met (Perks and Galantino, 2013). The connection to course and program related learning outcomes is essential to ensure the student demonstrates attainment of those outcomes, although there are broader aspects to consider when assessing the quality of assessment, particularly when that assessment is related to the competence to practice within pro- 
fessional programs. There has been much work undertaken guiding the design of assessment, indeed Baartman et al. (2006) argue that whilst individual tests of competency may not meet all quality indicators, the program as a whole should. According to Gardner and Van der Veer (1998), while an assessment is an imperfect process, it should still provide academics with rich insights into the ability of students to integrate, reflect and complete their under-graduate degrees with a sense of the meaning of their learning. (Baird, Gamble, \& Sidebotham, 2016)

Dikarenakan dua hal (penilaian kelas dan pembelajaran) merupakan aktivitas yang terencana dan terimplikasi dengan penuh kesadaran, maka keduanya harus dipersiapkan secara matang dan serius. Lebih lanjut, penilaian kelas tidak dapat meninggalkan suasana belajar di kelas, karena faktor suasana belajar di kelas menjadi bagian dari kondisi penilaian. Suasana belajar ikut menentukan kualitas penilaian autentik ini

Berdasarkan uraian di atas, maka kinerja guru sangat penting untuk ditingkatkan dan kenyataan di lapangan dapat diketahui bahwa guru yang bertugas pada dasarnya memiliki kinerja yang beragam. Untuk itu, menarik kiranya untuk mengangkat masalah ini menjadi masalah dalam pengabdian masyarakat khususnya di Kota Tangerang Selatan dan diharapkan dari masalah yang dikemukakan ditemukan jawaban serta solusi yang tepat demi kemajuan pendidikan. Berkaitan dengan hal tersebut, maka akan menjadi tepat sasaran jika pengabdian ini difokuskan untuk pendampingan dalam menyusun penilaian autentik yang digunakan dalam kurikulum 2013.

\section{PELAKSANAAN KEGIATAN}

A. Tempat dan Waktu

Kegiatan pendampingan

dilaksana-kan di Ruang Gambar SMKN

4 Tangerang Banten pada tanggal 4 Agustus 2018 sampai 1 September 2018 .

\section{B. Khalayak Sasaran}

Kegiatan ini dilakukan dengan melibatkan 15 orang guru SMKN 4 Tangerang Banten dari kompetensi keahlian Gambar Bangunan dan Geomatika.

\section{Metode}

Metode yang digunakan untuk pendampingan pengembangan instrumen penilaian autentik adalah ceramah, brainstorming, tanya jawab, Workshop, penugasan dan demonstrasi langsung. Ada 3 tahap yang dilaksanakan pada kegiatan ini, yaitu:

1. Pra-Kegiatan

Tahap pra-kegiatan dilakukan dengan cara: 1) persiapan pendampingan dilokasi serta penjelasan teknis kepada kepala SMK dan peserta pendampingan 2) penjelasan materi awal dan menetapkan sasaran 3) diskusi tentang penilaian autentik

2. Pelaksanaan Kegiatan

Pelaksanaan kegiatan dilakukan pendampingan pengembangan instrumen penilaian autentik pada mata pelajaran

3. Kegiatan Monitoring dan Evaluasi hasil Pendampingan

Kegiatan evaluasi instrumen dilakukan dengan diskusi tentang sejauh mana instrumen penilaian autentik yang telah dikembangkan. 


\section{HASIL DAN PEMBAHASAN}

Sebelum dilakukan proses pendampingan dilakukan rapat koordinasi dan penyamaan persepsi antara kepala sekolah, para wakil dan kepala-kepala kompetensi keahlian. Pada tahap ini dinyatakan oleh para pimpinan SMK 4 Tangerang. Seperti terlihat pada gambar di bawah ini:

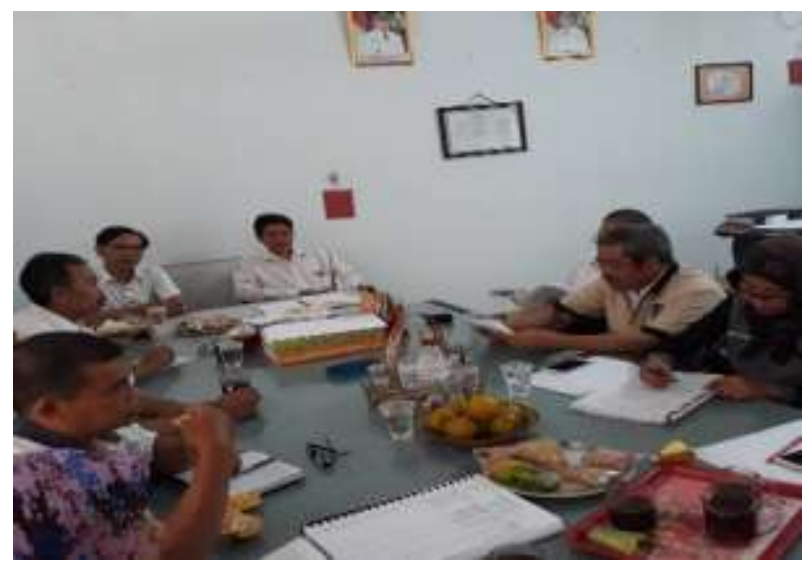

\section{Gambar 1. Rapat Koordinasi dengan Kepala SMKN 4 Tangerang beserta jajarannya.}

Pada kegiatan pra pendampingan
ini didapatkan masukan bahwa pendampingan hendaknya tidak hanya pada satu kompetensi keahlian Teknik Bangunan dan Geomatika saja. Para pimpinan SMKN 4 Tengerang bahwasanya menginginkan seluruh kompetensi keahlian yang ada di SMK tersebut diikutsertakan. Namun dikarenakan banyak kendala dan keterbatasan, maka dalam kegiatan pendampingan kali ini hanya berfokus pada Kompetensi keahlian Bangunan dan Geomatika.

Materi yang disampaikan dalam sesi pertama tanggal 4 Agustus 2018 pemaparan materi mengenai konsep penilaian autentik. Pada sesi kedua tanggal 11 Agustus 2018 peserta pelatihan melakukan Workshop penilaian Autentik berdasarkan mata pelajaran yang diampu setiap guru. Guru-guru peserta pelatihan menyusun indikator dan butir tes sebagai turunan dari Kompetensi Inti dan Kompetensi Dasar di masing-masing mata pelajarannya. Bagi guru yang telah melaksanakan penilaian autentik, maka kegiatan ini merupakan review bagi hasil pekerjaannya.

Tahapan pengembangan pendekatan penilaian autentik atau penilaian kelas (Chappuis, Stiggins, Chappuis, \& Arter, 2012) dapat pada tabel sebagai berikut:

Tabel 1. Penilaian Kompetensi Berbasis Kelas

\begin{tabular}{|c|c|c|}
\hline KEY OF QUALITY & COMPETENCIES & $\begin{array}{l}\text { HOW } \\
\text { RELATES } \\
\text { TO } \\
\text { EQUITY? }\end{array}$ \\
\hline $\begin{array}{l}\text { 1. Clear Purpose } \\
\text { Assessment processes and } \\
\text { results serve clear } \\
\text { and appropriate purposes. }\end{array}$ & $\begin{array}{l}\text { a. Identify the key users of classroom assessment } \\
\text { information and know what their information needs are. } \\
\text { b. Understand formative and summative assessment uses } \\
\text { and know when to use each. }\end{array}$ & \\
\hline
\end{tabular}




\begin{tabular}{|c|c|c|}
\hline KEY OF QUALITY & COMPETENCIES & $\begin{array}{c}\text { HOW } \\
\text { RELATES } \\
\text { TO } \\
\text { EQUITY? }\end{array}$ \\
\hline $\begin{array}{l}\text { 2. Clear Targets } \\
\text { Assessments reflect clear } \\
\text { student learning targets }\end{array}$ & $\begin{array}{l}\text { a. Know how to identify the five kinds of learning targets. } \\
\text { b. Know how to turn broad statements of content standards } \\
\text { into classroom-level learning targets. } \\
\text { c. Begin instructional planning with clear learning targets. } \\
\text { d. Translate learning targets into student-friendly language }\end{array}$ & \\
\hline $\begin{array}{l}\text { 3. Sound Design } \\
\text { Learning targets are } \\
\text { translated into } \\
\text { assessments that yield } \\
\text { accurate results }\end{array}$ & $\begin{array}{l}\text { a. Design assessments to serve intended formative and } \\
\text { summative purposes. } \\
\text { b. Select assessment methods to match intended learning } \\
\text { targets. } \\
\text { c. Understand and apply principles of sampling learning } \\
\text { appropriately. } \\
\text { d. Write and/or select assessment items, tasks, scoring } \\
\text { guides, and rubrics that meet standards of quality. } \\
\text { e. Know and avoid sources of bias that distort results }\end{array}$ & \\
\hline $\begin{array}{l}\text { 4. Effective } \\
\text { Communication } \\
\text { Assessment results } \\
\text { function to increase } \\
\text { student achievement. } \\
\text { Results are managed well, } \\
\text { combined appropriately, } \\
\text { and communicated } \\
\text { effectively. }\end{array}$ & $\begin{array}{l}\text { a. Use assessment information to plan instruction. } \\
\text { b. Offer effective feedback to students during the learning. } \\
\text { c. Record formative and summative assessment } \\
\text { information accurately. } \\
\text { d. Combine and summarize information appropriately to } \\
\text { accurately reflect current level of student learning. }\end{array}$ & \\
\hline $\begin{array}{l}\text { 5. Student Involvement } \\
\text { Students are active } \\
\text { participants in the } \\
\text { assessment process. }\end{array}$ & $\begin{array}{l}\text { a. Identify students as important users of assessment } \\
\text { information. } \\
\text { b. Share learning targets and standards of quality with } \\
\text { students. } \\
\text { c. Design assessments so students can offer peer feedback, } \\
\text { self-assess, and set goals for further learning on the basis } \\
\text { of the results. } \\
\text { d. Involve students in tracking, reflecting on, and sharing } \\
\text { their own learning progress }\end{array}$ & \\
\hline
\end{tabular}

Sumber: (Chappuis et al., 2012)

Adapun kegiatan tersebut dapat terlihat pada gambar di bawah ini:

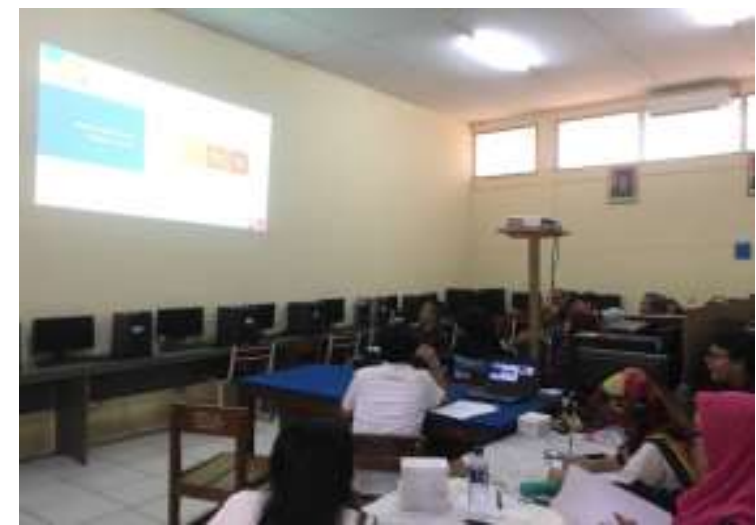

\section{Gambar 2. Pelaksanaan Pendampingan Penilaian Autentik}

Proses review pendampingan dan penilaian hasil akhir pendampingan 
mempertimbangkan hal-hal sebagai berikut: 1) Langkah-langkah kinerja yang diharapkan dilakukan peserta didik untuk menunjukkan kinerja dari suatu kompetensi yang hendak dicapai; 2) Kelengkapan dan ketepatan aspek yang akan dinilai dalam kinerja tersebut; 3) Kemampuan-kemampuan khusus yang diperlukan untuk menyelesaikan tugas; 4) Upaya kemampuan yang akan dinilai tidak terlalu banyak, sehingga semua dapat diamati; 5) Kemampuan yang akan dinilai diurutkan berdasarkan urutan yang akan diamati. (Komalasari, 2011, p. 153)
Walaupun kegiatan monitoring ini selalu berjalan semenjak sesi pertama, namun secara keseluruhan dilaksanakan pada tanggal 1 September 2018 berbarengan dengan penutupan kegiatan pendampingan ini. Adapun kriteria monitoring dan evaluasi didasarkan pada aspek: pemahaman tentang konsep dasar evaluasi, model dan jenis penilaian autentik, penyusunan butir dan rubrik serta penilaian praktik menulis butir penilaian autentik dengan kriteria minimum skor 80.

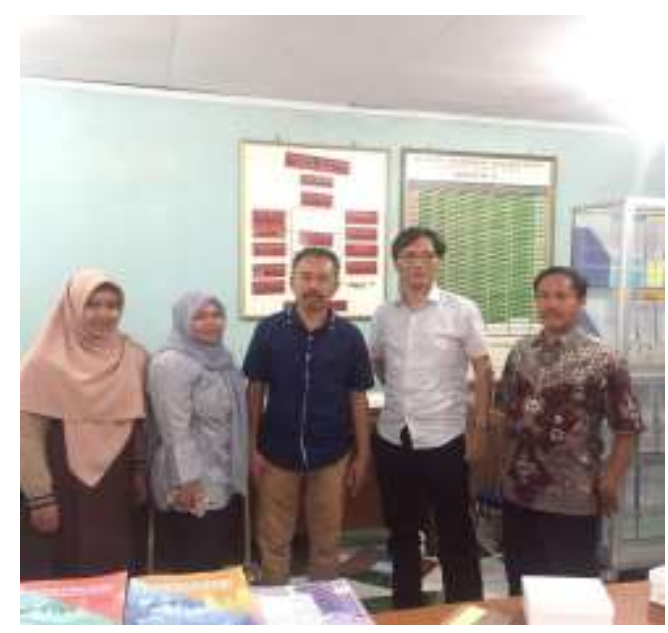

\section{Gambar 3. Monitoring dan Evaluasi Hasil Pendampingan}

Hasil karya guru dikumpulkan, diberi masukan dan selanjutnya diperbaiki kembali. Selama proses penulisan dilakukan tanya jawab dan diskusi antar peserta dan pengabdian untuk meningkatkan pemahaman sehingga akan memperoleh hasil yang diinginkan.

Komponen yang diterapkan dalam evaluasi kerja, yaitu: 1) Penilaian unjuk kerja adalah proses, bukan suatu tes atau pengukuran tunggal. 2) fokus proses ini adalah mengumpulkan informasi dengan menggunakan berbagai pengukuran dan strategi. 3) data dikumpulkan melalui suatu pengamatan yang sistemik. Penekanannya pada teknik pengamatan langsung bukan hanya pada ujian tertulis saja. 4) data dipadukan untuk menentukan kebijakan dan 5) subjek penentuan kebijakan adalah individu bukan program atau produk (Mardapi, 2012, pp. 12-17)

Berdasarkan hasil kegiatan peserta pengabdian memahami konsep penilaian autentik dan pada dasarnya guru-guru belum terbiasa, walaupun terkadang para guru sebenarnya sudah melaksananya pada kegiatan sehari-hari. Hasil dari pelatihan ini langsung dilaporkan kepada kepala sekolah dan 
disaksikan oleh pengawas sekolah sebagai fasilitatornya.

Kegiatan pengabdian masyarakat dengan melaksanakan pendampingan tentang pengembangan penilaian Autentik untuk meningkatkan kinerja bagi Guru di SMKN 4 Tangerang Selatan berjalan dengan tertib dan sesuai rencana. Pendampingan penilaian autentik ini dibutuhkan bagi guru. Hasil pelatihan akan kurang bermanfaat bagi guru jika tidak dilaksanakan secara berkesinambungan. Oleh karena itu, guru merasakan banyak manfaat yang diperoleh dari pendampingan ini agar mengalami peningkatan kemampuan dalam mengembangkan penilaian autentik untuk meningkatkan kinerja guru.

Guru hendaknya juga bertanggung jawab atas tugas profesionalnya. Agar ilmu yang dimilikinya dapat berkembang dan tidak tertinggal, guru seyogianya melakukan kajian keilmuan yang menjadi bidangnya. Agar kajian yang dilakukannya bermanfaat bagi orang banyak/guru lain, maka sebaiknya pelatihan ini juga dimanfaatkan sebagai evaluasi diri untuk lebih meningkatkan kualitas proses penilaian yang selama ini dilakukan.

\section{Hasil Evaluasi}

Evaluasi kegiatan pengabdian masyarakat ini dilakukan setelah berakhirnya kegiatan. Indikator pencapaian keberhasilan kegiatan ini mengacu kepada target luaran yang sudah dijelaskan pada bab dua. Berdasarkan parameter evaluasi tersebut menunjukkan bahwa kegiatan pengabdian masyarakat terlaksana sesuai agenda yang telah direncanakan sehingga guru memiliki pengetahuan dan pemahaman yang tepat tentang bagaimana mengembangkan penilaian autentik pada masing-masing mata pelajaran.

Pada materi konsep dasar evaluasi pada umumnya guru-guru belum memiliki kemampuan yang memadai. Hal ini dibuktikan dari hasil tes hanya $30 \%$ guru yang memiliki kemampuan dalam menjelaskan konsep dasar evaluasi secara komprehensif dengan skor rata-rata sebesar 60,67 dan kriteria skor minimum 80.

Senada dengan kondisi tersebut dikatakan oleh Castellano et.al (2017, pp. 54-55) seseorang yang terbiasa pada ranah terapan, umumnya memiliki kesulitan tersendiri jika harus kembali menjelaskan konsep dasar dari sebuah ilmu. Begitu pun sebaliknya seseorang yang terbiasa dalam konsep teori dan ilmu dasar, maka akan butuh waktu untuk menerjemahkan ilmu tersebut dalam kegiatan pratik (Goh \& Zukas, 2016, pp. 3-10).

Uraian materi tentang model dan jenis penilaian autentik sepertinya merupakan materi yang terbilang baru bagi para guru. Hal ini dibuktikan hanya $30 \%$ guru yang sudah paham dengan model dan jenis penilaian autentik. Namun demikian, berdasarkan hasil evaluasi guru cepat dalam memahaminya karena secara praktik para guru pada dasarnya telah melaksanakannya pada kesehariannya. Kondisi ini dibuktikan dari hasil evaluasi $80 \%$ guru dapat memberikan penjelasan dan contoh-contoh model dan jenis penilaian autentik dengan skor rata-rata 72 .

Hasil tersebut sejalan dengan Sani (2016, p. 24) yang mengatakan bahwa penilaian autentik adalah jenis penilaian yang mengarahkan peserta didik untuk mendemonstrasikan keterampilan dan kompetensi yang dibutuhkan untuk mengatasi permasalahan dan situasi yang dijumpai dalam kehidupan nyata 
Praktik menulis butir penilaian autentik adalah kegiatan yang paling menyita waktu dan energi. Oleh karena itu, kegiatan ini akhirnya dibagi pada 2 sesi pendampingan. Sesi pertama fokus pada penulisan soal berbasis kompetensi dan sesi keduanya fokus pada penyusunan rubrik.

Berdasarkan hasil evaluasi guruguru telah memiliki kompetensi dalam menulis butir ini, hanya saja pada penyusunan rubrik penilaiannya masih banyak kendala. Terutama pada gradasi rubrik. Kondisi ini dibuktikan baru $80 \%$ guru yang memiliki skor di atas 80 sebagai kriteria pencapaian pendampingan dengan skor rata-rata 83,67 .

Hasil di atas dapat dipahami karena adanya faktor yang mendukung berjalannya kegiatan pendampingan. Hal-hal yang mendukung berjalannya kegiatan pengabdian ini dapat diidentifikasi diantaranya antusiasme para peserta pelatihan untuk memahami konsep penilaian Autentik. Hal ini dibuktikan dengan pertanyaan yang muncul mengenai konsep dasar dan penerapan penilaian autentik, pengerjaan tugas yaitu pengembangan penilaian autentik pada mata pelajaran masingmasing serta selalu hadir selama pelatihan. Selain itu, peran ketua jurusan Teknik Gambar Bangunan memberikan arti penting sebagai upaya mendorong agar guru fokus pada pendampingan mengembangkan penilaian autentik ini.

Kenyataan di atas sejalan dengan pendapat Arthur (2018) yang menyatakan bahwa dukungan lingkungan kerja, teman sejawat dan pimpinan memberikan dorongan yang cukup besar bagi keberhasilan sebuah pelatihan atau pendampingan.

Lancarnya pelaksanaan kegiatan pengabdian bukan berarti tanpa hambatan selama pengabdian. Selama pengabdian ada beberapa hal yang diidentifikasi sebagai faktor penghambat kegiatan pengabdian diantaranya adalah rendahnya kemampuan awal guru bagi sebagian peserta pendampingan. Melakukan penilaian merupakan kegiatan yang tidak hanya membutuhkan kemampuan akan tetapi juga membutuhkan ketelitian. Banyak guru yang mempunyai kemampuan untuk menulis butir tes dan melaksanakan penilaian autentik akan tetapi kurang teliti dan mengalami 'kejenuhan setelah seharian melaksanakan tugas mengajarnya. Hal ini disebabkan kurangnya kesempatan yang diberikan dan dorongan motivasi dari pihak sekolah maupun dinas pendidikan mengenai pentingnya menyusun evaluasi dan penilaian sendiri oleh guru yang bersangkutan.

\section{PENUTUP}

Kegiatan pendampingan tentang Pengembangan Penilaian Autentik untuk meningkatkan kinerja guru. Penguasaan metode konsep dan penyusunan instrumen tes maupun non tes dapat dipahami secara saksama. Di samping itu, berdasarkan review dari kepala Jurusan Teknik Gambar Bangunan SMKN 4 Tangerang instrumen penilaian autentik yang dihasilkan oleh guru masih perlu pembenahan untuk di awal pelatihan ini.

Kemampuan guru dalam menyusun penilaian autentik masih rendah karena kurangnya latihan dan kurang adanya kemauan untuk menulis. Namun demikian dengan adanya pelatihan-pelatihan semacam ini guru dapat meningkatkan pengetahuan dan wawasan serta memacu motivasinya sendiri. Dengan sendirinya hal tersebut akan menunjang penguasaan kompetensi profesional guru. 
Berdasarkan tanggapan dan pertanyaan peserta pengabdian, dalam hal ini peserta, maka saran yang dapat diberikan adalah agar guru dapat mengembangkan kreativitasnya dalam mengembangkan berbagai bentuk penilaian autentik. Untuk selanjutnya guru meminta pelatihan serupa dapat dilaksanakan kembali dengan peserta yang lebih mendalam.

\section{DAFTAR PUSTAKA}

Arthur, R. (2018). Evaluasi Program Diklat Karya Tulis Ilmiah Untuk Widyaiswara Pusbangtendik Kemdikbud. Jurnal Penelitian Dan Evaluasi Pendidikan, 22(1), 35-48. https://doi.org/10.21831/pep.v22i1. 16749

Baird, K., Gamble, J., \& Sidebotham, M. (2016). Assessment of the quality and applicability of an e-portfolio capstone assessment item within a bachelor of midwifery program. Nurse Education in Practice, 20, 11-16. https://doi.org/10.1016/j.nepr.2016 .06 .007

Brookhart, S. M. (2003). Developing measurement theory for classroom assessment purposes and uses. in Practice, 20, 125-130. https://doi.org/10.1016/j.nepr.2016 .08 .002

Goh, A. Y. S., \& Zukas, M. (2016). Student vocational teachers: The significance of individual positions in workplace learning. Journal of Vocational Education and Training, 68(2), 263-277. https://doi.org/10.1080/13636820.2 016.1172661

Komalasari, K. (2011). Pembelajaran Kontekstual Konsep dan Aplikasi. Bandung: Refika Aditama.

Mardapi, D. (2012). Pengukuran
Educational Measurement: Issues and Practice, 22(4), 5-12. https://doi.org/10.1111/j.17453992.2003.tb00139.x

Calenda, M., \& Tammaro, R. (2015). The Assessment of Learning: From Competence to New Evaluation. In INTE (Vol. 174, pp. 3885-3892). Elsevier B.V. https://doi.org/10.1016/j.sbspro.20 15.01.1129

Castellano, M. E., Richardson, G. B., Sundell, K., \& Stone, J. R. (2017). Preparing Students for College and Career in the United States: the Effects of Career-Themed Programs of Study on High School Performance. Vocations and Learning, 10(1), 47-70. https://doi.org/10.1007/s12186016-9162-7

Chappuis, J., Stiggins, R. J., Chappuis, S., \& Arter, J. A. (2012). Classroom Assessment for Student Learning: Doing It Right_-Using It Well (2nd ed.). New Jersey: Pearson.

Chong, E. J. M., Lim, J. S. W., Liu, Y., Lau, Y. Y. L., \& Wu, V. X. (2016). Improvement of learning domains of nursing students with the use of authentic assessment pedagogy in clinical practice. Nurse Education Penilaian dan Evaluasi Pendidikan (1st ed.). Yogyakarta: Nuha Medika.

Raymond, J. E., Homer, C. S. E., Smith, R., \& Gray, J. E. (2013). Learning through authentic assessment: An evaluation of a new development in the undergraduate midwifery curriculum. Nurse Education in Practice, 13(5), 471-476. https://doi.org/10.1016/j.nepr.2012 .10 .006

Sani, R. A. (2016). Penilaian Autentik. Jakarta: Bumi Aksara. 